\title{
Research on Target Matching of Television Guided Missile Seeker
}

\author{
Wei CHEN ${ }^{1 *}$, Fancheng $\mathrm{KONG}^{1}$, Di ZHANG ${ }^{1}$, Zhenzhou BAI ${ }^{2}$ \\ ${ }^{1}$ Air Force Logistics Academy, Xuzhou Jiangsu, 221000, China \\ ${ }^{2} 95937$ Troops, Fuxin Liaoning, 123000, China \\ E-mail: chenweijiangyiwa@126.com \\ +* Corresponding author
}

\begin{abstract}
Target matching research of TV precision-guided weapons, is whether the analysis according to the principle of TV seeker intercept missiles to intercept and hit the target. The paper used intercepting and tracking algorithm of TV-guided missile seeker, to attack simulated the target simulation images, theoretically determines the above two missile seeker's stability to intercept and track the target, and then used simulation results to guide the flight of the missile.
\end{abstract}

\section{Keywords-target matching; television guided missile; seeker}

\section{INTRODUCTION}

Target matching of TV-guided missile seeker has big computation and complicated calculation method, through making research on the all kinds of spring type seeker intercept algorithm which complying with the principle, and analyzed the satellite photos or investigation photographs which from intelligence department, and determined whether to carry weapons intercepted and hit the target, formed between the weapon and the target to be the integral part of the closed loop, and helped to improve the target analysis ability of troops on the battlefield, improved the operational effectiveness of weapons, perfected the task planning system of our army ${ }^{[1-2]}$.

\section{INTERCEPTING PRINCIPLE TELEVISION GUIDED MISSILE}

The television guided missile seeker tracked the target images. The seeker of memory is not a goal of brightness and contrast, it's just a memory target designation phase, can see the picture, images of the target contrast. Correlation tracking is a form of tracking in imaging guidance. Correlation tracking measurement of the same scene image displacement of two don't have time, one of the images is called a baseline images, it can be a measurement which has been the target of the image, also can be determined in advance and stored image. The other is the image which is received, and the target image which the seeker has just "seen". The related function of the two images is first obtained, and then the error signal of the target position is obtained by a certain relationship. The automatic pilot is guided by the target position error signal based on the seeker's head.

\section{The TV Guided Bomb InTERCEPTING AlgORITHM}

The paper used an image matching algorithm to evaluate the target matrix $\mathrm{t}$ and the matching matrix $\mathrm{s}$ similarity in the formula (1):

$$
\begin{gathered}
\mathrm{D}(\mathrm{i}, \mathrm{j})=\sum_{\mathrm{m}=1}^{\mathrm{M}} \sum_{\mathrm{n}=1}^{\mathrm{N}}\left[\mathrm{s}^{\mathrm{ij}}(\mathrm{m}, \mathrm{n})-\mathrm{t}(\mathrm{m}, \mathrm{n})\right]^{2} \\
=\sum_{\mathrm{m}=1}^{\mathrm{M}} \sum_{\mathrm{n}=1}^{\mathrm{N}}\left[\mathrm{s}^{\mathrm{ij}}(\mathrm{m}, \mathrm{n})\right]^{2}-2 \sum_{\mathrm{m}=1}^{\mathrm{M}} \sum_{\mathrm{n}=1}^{\mathrm{N}} \mathrm{s}^{\mathrm{ij}}(\mathrm{m}, \mathrm{n}) \times \mathrm{t}(\mathrm{m}, \mathrm{n})+\sum_{\mathrm{m}=1}^{\mathrm{M}} \sum_{\mathrm{n}=1}^{\mathrm{N}}[\mathrm{t}(\mathrm{m}, \mathrm{n})]^{2}
\end{gathered}
$$

In formula (1) of the first item is match matrix s energy, the last item is the energy of target matrix $t$, middle is the target matrix $t$ and matching matrix $s$ number of mutual relations, the as $(i, j)$. When the match area and target window are matched, the middle term has a maximum value, which is normalized, and the correlation coefficients for the matching region and target window are available:

$$
\mathrm{R}(\mathrm{i}, \mathrm{j})=\frac{\sum_{\mathrm{m}=1}^{\mathrm{M}} \sum_{\mathrm{n}=1}^{\mathrm{N}} \mathrm{s}^{\mathrm{ij}}(\mathrm{m}, \mathrm{n}) \times \mathrm{t}(\mathrm{m}, \mathrm{n})}{\sqrt{\sum_{\mathrm{m}=1}^{\mathrm{M}} \sum_{\mathrm{n}=1}^{\mathrm{N}}\left[\mathrm{s}^{\mathrm{ij}}(\mathrm{m}, \mathrm{n})\right]^{2}} \sqrt{\sum_{\mathrm{m}=1}^{\mathrm{M}} \sum_{\mathrm{n}=1}^{\mathrm{N}}[\mathrm{t}(\mathrm{m}, \mathrm{n})]^{2}}}
$$

The correlation coefficient (i, j) has a value of 1 when the matching area and target window are fully overlapping. The algorithm used formula (2) to calculate the correlation coefficient $\mathrm{R}$ of each matching area and the target window value, when the correlation coefficient $R$ value is greater than the setting threshold set to match the center point, and then combined with other conditions in the center of the have figured out the matching points screening to get the final match point real-time graph, complete the image matching.

The error of the center point $E(i, j)$ of the target area, and the error of the match center point $E(i, j)$, is expressed in terms of the error ratio $\mathrm{E}$.

$$
E(i, j)=\frac{\sqrt{\left(i_{\mathrm{E}}-\mathrm{i}_{\mathrm{e}}\right)^{2}+\left(\mathrm{j}_{\mathrm{E}}-\mathrm{j}_{\mathrm{e}}\right)^{2}}}{\sqrt{\mathrm{H}^{2}+\mathrm{L}^{2}}}
$$

When using a television guided bomb to attack a ground target, the television guided bomb seeker intercepts the first image, measuring the image, when the input button is pressed. Depending on the program, the size and Angle of the target image seen by the seeker will change as the distance draws closer. At this time, the guide head USES the above formula, the relative coefficients of the two images are 
calculated according to the resolution size of the frame. Here's how:

1) When the seeker's head intercepts the measurement image, it is obtained by the size of the resolution of the image to obtain the gray value of each pixel of the image, such as Fig. 1, as shown in Fig. 1.

2) Because the TV guided bomb in grey value when used for simulation calculation, thus got the row or column of a set of simulated data values, such as Fig. 2.

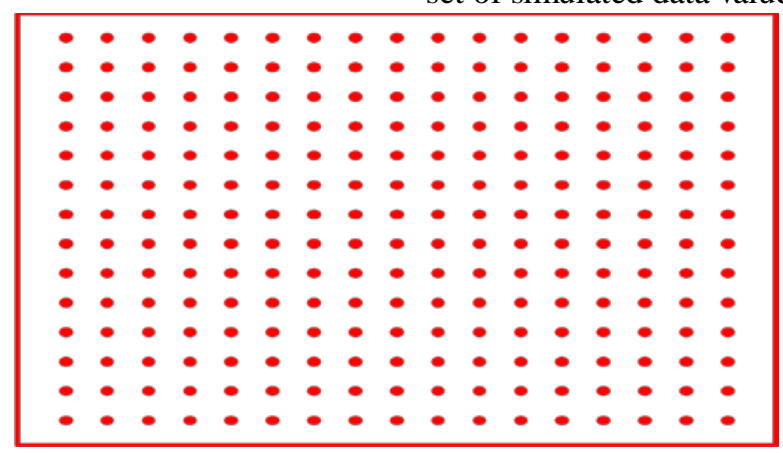

Figure 1. Measuring the gray value per pixel

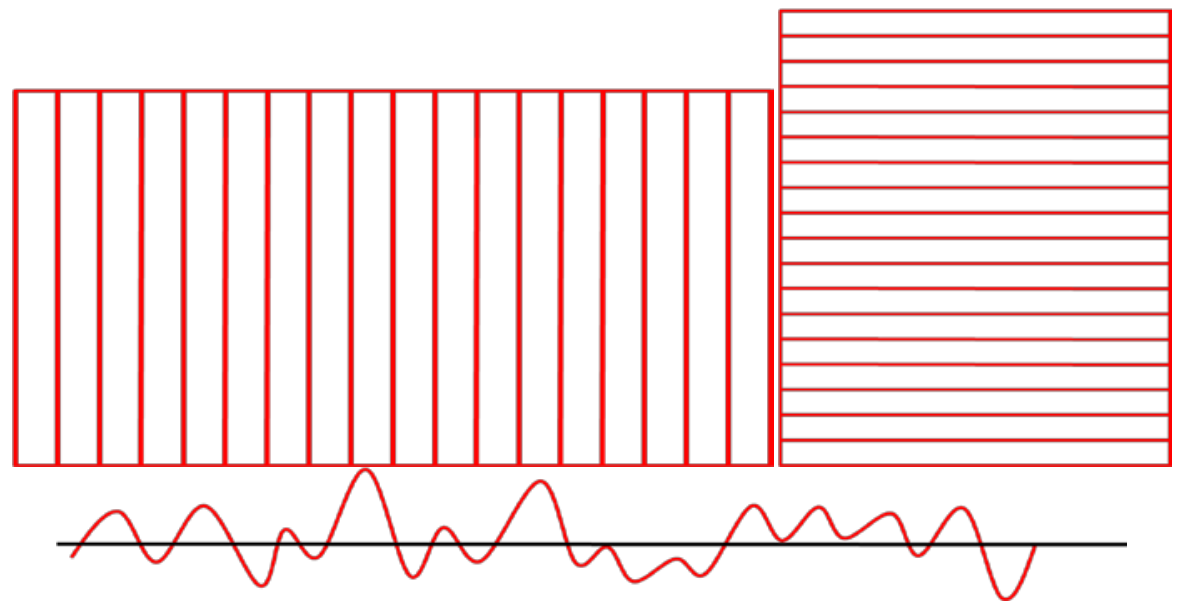

Figure 2. Measuring the gray value per pixel

3) Affected by the computing power of TV guided bombs, in acquiring each row or column of the data, the seeker for each row or column to capture the data, in order to reduce amount of calculation, meet the requirements of the speed of the stable intercepted TV guided bombs, such as Fig. 3 shows.

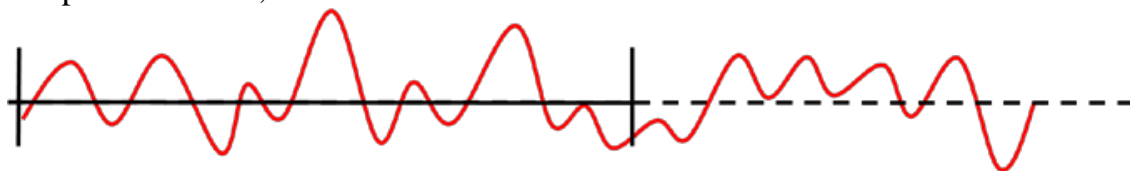

Figure 3. The Seeker intercepts data per row or column

4) After obtaining the data of the measurement image, repeat the above steps to obtain the data about the receiving image.

5) The relative coefficient of each point is calculated by using the correlation coefficient, as shown in Fig. 4.

To measure the image as the base, to get the image comparison, to measure the image on the horizontal to move $\mathrm{n}$ pixels to the left, to find the rho value of the moving phase. In this case, the gray value of the pixels above the location is calculated as " 0 ". Then move sideways to the right by 1 pixel, which is the value of the point, until the right is moved to $n$ pixels.

Likewise, move a pixel in the vertical direction, and then fetch the rho value of a point again. Finally, you get a list of row values array of two images, such as Fig. 5. 


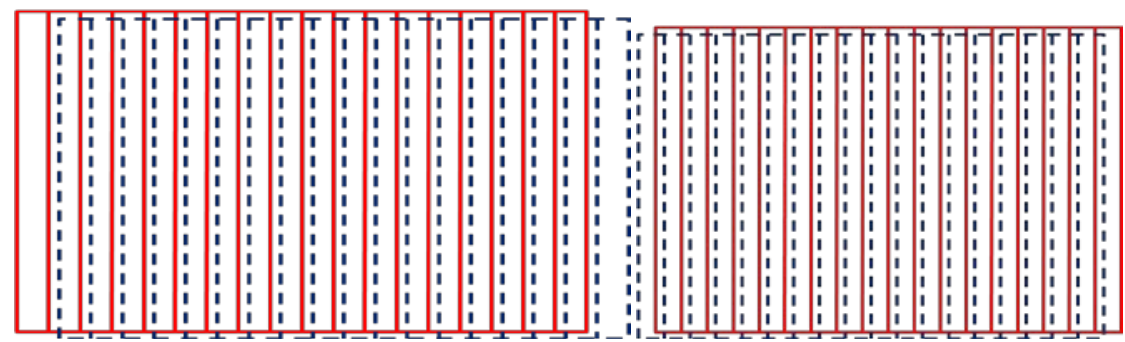

Figure 4. The correlation coefficients per point

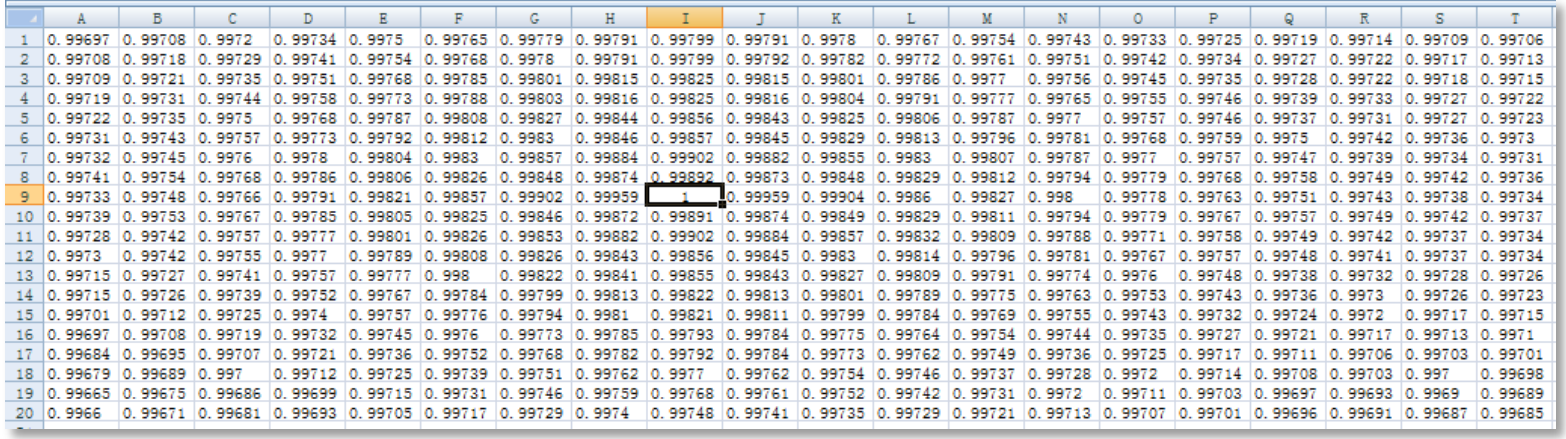

Figure 5. Taking 20 points along the $\mathrm{X}$ and $\mathrm{Y}$ axis

Using the list of rho values, the two images can be drawn in a three-dimensional curve, such as Fig. 6.

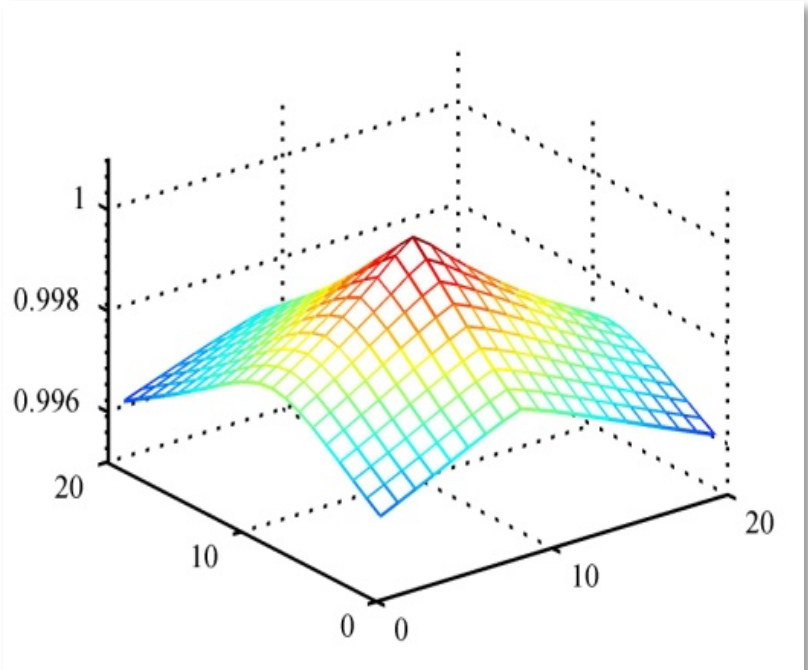

Figure 6. 3d curve distribution

7. Calculate the picture along the $\mathrm{X}, \mathrm{Y}$ axis variance values of two directions, according to the size of the value of variance and the steep in the central regions of the image, determine whether seeker TV guided bombs on the target to intercept.

\section{SUMMARY}

The paper makes research on the target seeker TV guided Missile matching algorithm, can solve the seeker TV guided bombs can intercept and target tracking problem, which provide good practice for the future and live firing reference, increasing the service efficiency of TV guided bombs, avoid caused by stable seeker can't intercept missile to launch, or missile impact from target larger problem from happening again.

\section{REFERENCE}

[1] ZHANG Dong-bo, WANG Yao-nan. Fuzzy-rough Neural Network and Its Application to Vowel Recognition[J]. Control and Decision, 2013,21(2):221-224.

[2] GAO Jian,TONG Ming-an .Extracting decision rules for cooperative team air combat based on rough set theory[J].Chinese Journal of Aeronautics,2013,16(4) :223-228.

[3] CHEN Qi-shun. Calculation manual of aircraft Flight performance [M]. Beijing. Flight Mechanics journal press, 2007.

[4] D. Ballard and L. Rippy. A Knowledge-Based Decision Aid for Enhanced Situation Awareness [C]. IEEE/AIAA Digital Avionics Conference,2015,310 347

[5] D.L. Hall. Lectures in Multisensor Data Fusion and Target Tracking [C]. Xi'an, China, 2012

[6] J. Azarewzcz,G Fala and C,Heithecher. Template-Based Multi-Agent Plan Recognition for Tactical Situation Assessment [C]. In Proceedings of 5th conference on Artificial Intelligence Applications, March 2011,247 254. 